\title{
Numerical Simulation of Q345 Steel Pipe Joint Weld
}

\author{
Guoqiang Wu \\ Tianjin Maritime College, Tianjin, 300350 China
}

\begin{abstract}
Q345 steel pipe is a commonly used welding material. Whether it is shipbuilding, boiler pressure vessel or construction engineering, the demand for Q345 steel is very large. In this paper, the numerical simulation of Q345 steel pipe is carried out. It is analyzed whether the temperature field and stress field of the welded joint are similar to the reality under the condition of two-layer weld seam, so as to prove that the welding process can be implemented accordingly.
\end{abstract}

\section{Establishment of finite element model}

In the modeling, the length of the cylinder was set to 100 $\mathrm{mm}$, the weld height was set to $2 \mathrm{~mm}$, and the number of weld layers was set to 2 layers. After the basic 2D framework model is built, it is meshed. During the welding process, the temperature gradient is very large, and the meshing is unevenly divided. The closer to the weld is, the denser the mesh is ${ }^{[1]}$, and the mesh is far from the weld, and the mesh is loose. The established 3D model diagram is shown in Figure 1.

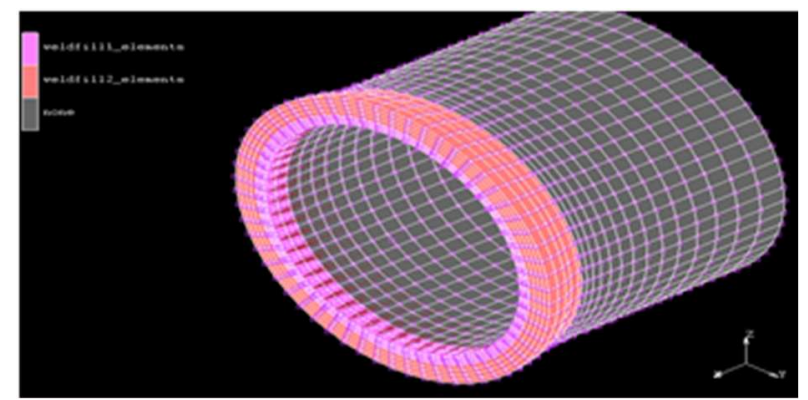

Figure $13 \mathrm{D}$ model generation

\section{Establish a welding path}

The weld shape of this experiment is a ring weld ${ }^{[2]}$. According to the welding process, it is divided into two layers of welds, so there are two welding paths defined. After the solder layer is set, the soldering path and direction can be seen by turning off the display of the nodes and cells. The welding path of the arc is composed of a small linear welding path, and the welding path is the tangential direction of these nodes, that is, the $\mathrm{Z}$ direction. The arc direction of the weld is downward, i.e. Y-direction ${ }^{[3]}$. The welding path is shown in Figure 2.

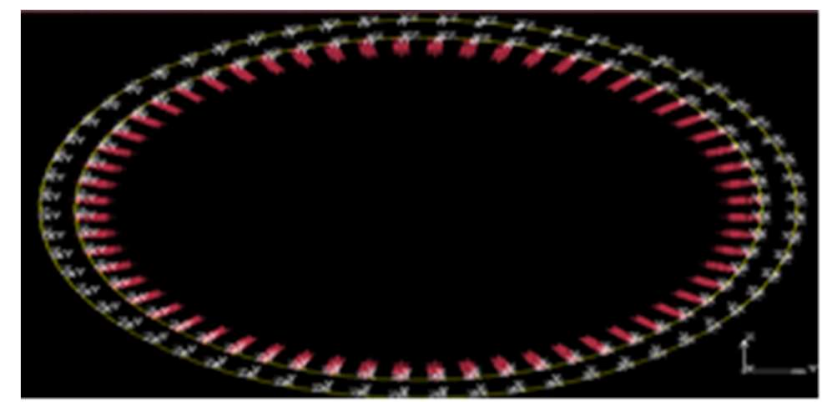

Figure 2 Welding path display

\section{Applying boundary conditions}

\subsection{Selection of welding heat source}

The heat source model used in this paper is a double ellipsoidal sphere, and the simulation process assumes that the welding material and the parent material have the same performance characteristics. The double ellipsoid model is shown in Figure 3.

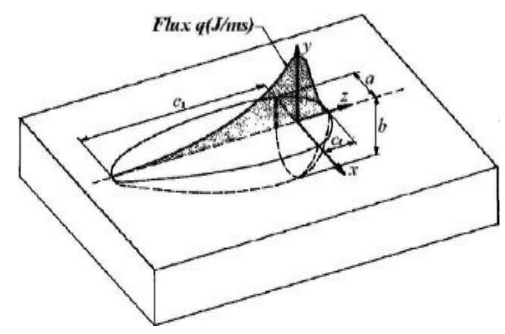

Figure 3 Double ellipsoid heat source model

During the simulation, some parameters of the heat source are given. The given heat source parameters are shown in Table 1: 
Table 1 Heat source parameter table

\begin{tabular}{|c|c|c|c|c|c|}
\hline $\begin{array}{c}\text { Number } \\
\text { of weld } \\
\text { layers }\end{array}$ & $\begin{array}{c}\text { Heat } \\
\text { source } \\
\text { width } \\
(\mathrm{mm})\end{array}$ & $\begin{array}{c}\text { Heat } \\
\text { source } \\
\text { depth } \\
(\mathrm{mm})\end{array}$ & $\begin{array}{c}\text { Front } \\
\text { half } \\
\text { shaft } \\
(\mathrm{mm})\end{array}$ & $\begin{array}{c}\text { Rear } \\
\text { half } \\
\text { shaft } \\
(\mathrm{mm})\end{array}$ & $\begin{array}{c}\text { Welding } \\
\text { speed } \\
(\mathrm{mm} / \mathrm{s})\end{array}$ \\
\hline 1 & 5 & 2.5 & 3 & 15 & 2 \\
\hline 2 & 8 & 3 & 4 & 16 & 3 \\
\hline
\end{tabular}

\subsection{Setting of thermal boundary conditions}

When the thermal boundary condition is set, the convective heat transfer surface of the model is the contact surface between the workpiece and the air. The inner surface, the outer surface and the end surface of the workpiece are in contact with the air, and thermal boundary conditions are required ${ }^{[4]}$. The model pattern after setting the thermal boundary conditions is shown in Figure 4:

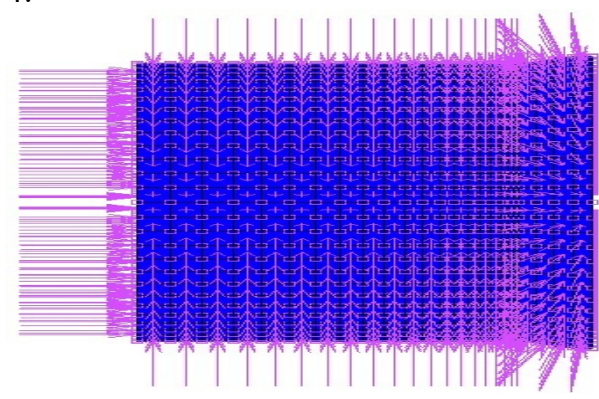

Figure 4 Thermal boundary conditions

\section{Working conditions setting and operation}

During the simulation, the two-layer welds need to be set separately. Each layer needs to be set for the cooling time and time step. The cooling time is consistent with the parameters of the time step.

When the cooling process is set, all weld boundary conditions need to be canceled, and the estimated cooling time and the detection increment time step are given. The set working condition pattern is shown in Figure 5.

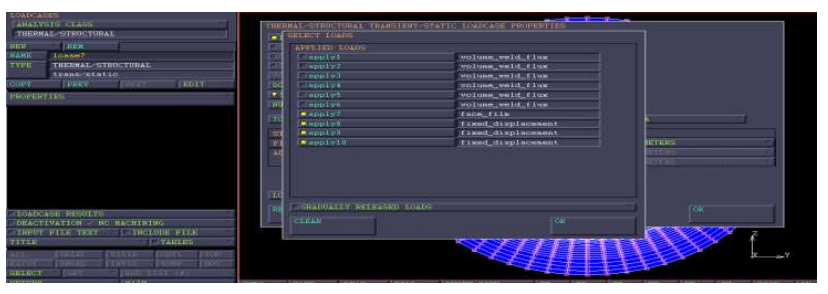

Figure 5 Working condition setting pattern of the cooling process

\section{Simulation results analysis}

The analysis process of the simulation results is very complicated, and the analysis time is proportional to the complexity of the model. After the end of the simulation process, the display is exactly 3004 after exiting, thus indicating that the analysis process is correct.

\subsection{Analysis of temperature field results}

The calculation results can be viewed in the interface, and the temperature field of the welding process can be viewed every second. The following is an example of a temperature field distribution map selected for each weld seam, as shown in Figure 6.

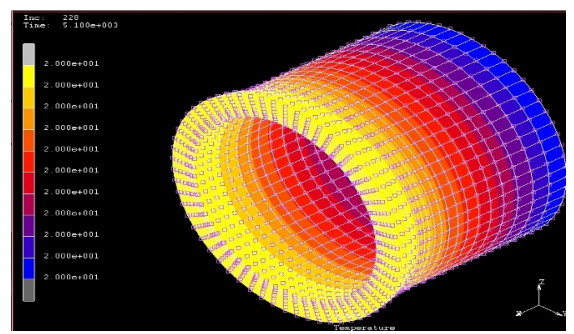

(a)

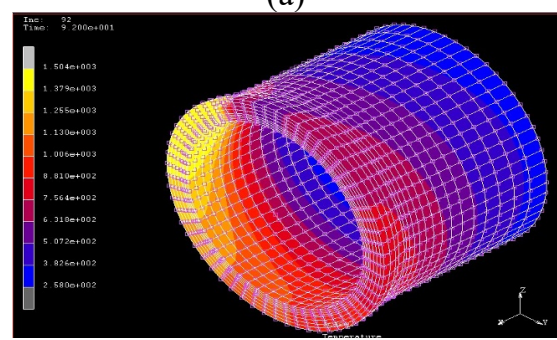

(b)

Figure 6 Temperature field (a) (b)

As shown in the above figure, the excerpts are the temperature field distribution maps of 92 steps and 228 steps, respectively. Step 92 is the temperature field generated by the first layer of the weld. The melting point of the weld is set to $1500{ }^{\circ} \mathrm{C}$, which is consistent with the initial setting. The 228 step is the temperature field at the end of the second layer. At this time, the weld has been Down to room temperature, the bar code on the left shows that the test piece temperature is $20^{\circ} \mathrm{C}$, which also matches the initial set value.

In order to better observe the distribution law of temperature field at different locations, firstly, three nodes with different distances from the weld zone are randomly selected on the model, and the thermal cycle curve is analyzed. The selected node location is shown in Figure 7:

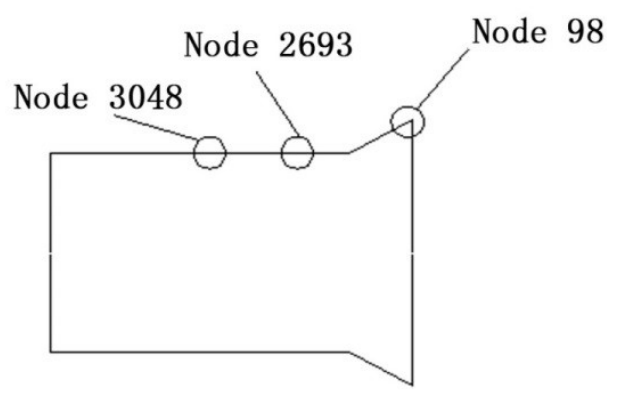

Figure 7 Node selection location map 


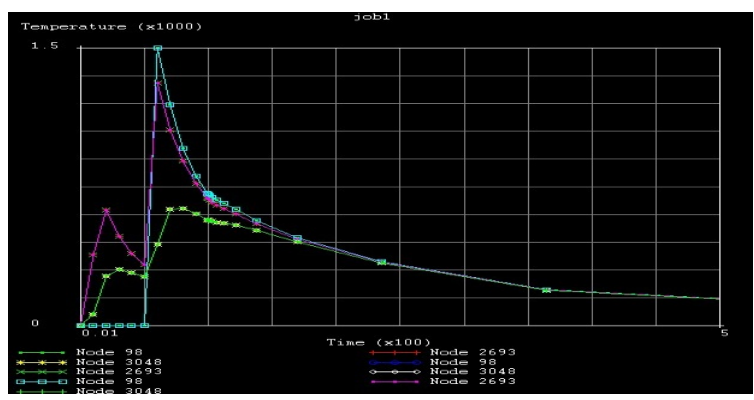

Figure 8 Thermal cycling curve of three nodes

It can be seen from Fig. 8 that the thermal cycling process of node No. 2693 and node No. 3048 occurs at the same time, the peak of the curve of node No. 98 is the highest, and the thermal cycle process of this point occurs on the second layer of the bead. The curve peak of node 3048 is the lowest. This is a reaction to the phenomenon that the No. 98 node is on the second layer of weld. During the welding process, the point receives the most heat and the temperature is the highest; the No. 3048 node is farthest from the weld zone, during the welding process. The heat is minimal and the temperature is lowest. This has exactly one-to-one correspondence with the position when the node is selected, indicating that this thermal cycle is realistic.

\subsection{Analysis of stress field results}

In the simulation process, the welding residual stress generated during the welding process was also analyzed, and the analysis results are shown in Fig. 9.

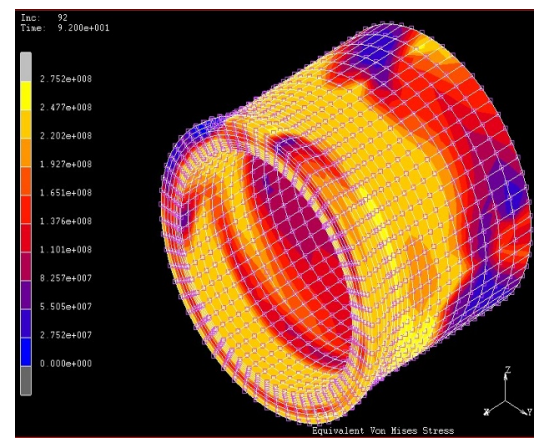

(a)

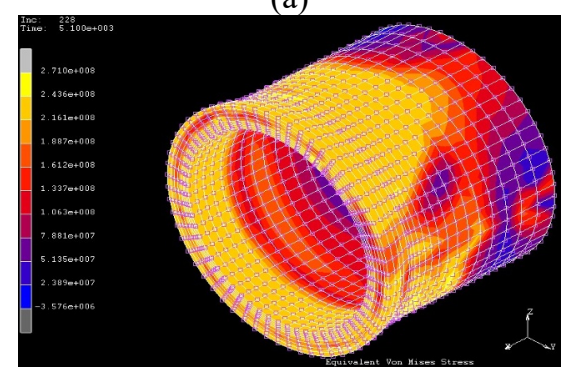

(b)

Figure 9 Stress field (a) (b)
Figure 9 shows the equivalent stress field model of steps 92 and 228. It can be seen from the figure that after the welding process is completed, the residual stress value of the first layer of weld is the smallest, which is because the weld of the post weld has the effect of thermal stress on the first weld, and the first weld is reduced. Participation in stress. After cooling to room temperature, the residual stress value in the weld zone was $271 \mathrm{Mpa}$.

\section{Summary}

In this paper, the numerical simulation of temperature field and stress field is carried out for Q345 steel pipe weld. Several nodes in different regional locations were selected, and the corresponding distribution rules were obtained, which are summarized as follows:

(1) There is heat transfer during the welding process. The temperature at the center of the weld is the highest. The closer to the base metal on both sides, the lower the temperature. During the simulation, the melting point temperature of the metal was set to $1500{ }^{\circ} \mathrm{C}$, and the ambient temperature was set to $20^{\circ} \mathrm{C}$. During the welding process, the temperature at the center of the weld is $1500{ }^{\circ} \mathrm{C}$, and the closer to the side of the base metal, the lower the temperature. This is because the heat is transferred to the base metal on both sides during the welding process, and therefore, the temperature of the base material is higher than the ambient temperature. When cooled to room temperature, the temperature of the entire weldment was $20^{\circ} \mathrm{C}$. This result is consistent with the experimental settings. The selected nodes have thermal cycle curves that conform to the actual laws.

(2) The selection of the stress field nodes also proves the correctness of the welding process. The residual stress value of the weld zone after welding is $271 \mathrm{Mpa}$. If the number of weld layers is small, the residual stress value after welding will be lower.

\section{References}

1. Zhang Yanchong. Research on lightweight design method and performance optimization of a SUV frame [J]. Chinese Excellent Master's Thesis Full-text Database, 2015.

2. Yi Zhengqing, Xi Deke, Lu Lin, Zhao Xu, Sun Gang. Numerical simulation and experimental study of free fan $[\mathrm{J}]$. Mechanical Design and Manufacturing, 2007, (10): 102-103.

3. Wu Hao. Research on large flow safety valve for hydraulic support [J]. Chinese Excellent Master's Thesis Full-text Database, 2012.

4. Dong Zhibo, Wei Yanhong, Liu Renpei, Dong Zuyu. Three-dimensional numerical simulation of stainless steel welding temperature field $[\mathrm{J}]$. Journal of Welding, 2004 (02). 